De opmars van de militaire geschiedenis

\title{
W. KLINKERT
}

Bespreking van: J. R. Bruijn, C. B. Wels, ed., Met man en macht. De militaire geschiedenis van Nederland 1550-2000 (Amsterdam: Balans, 2003, 463blz, €35,-, ISBN 905018600 9).

'Goede militaire geschiedschrijving is er wel, maar integratie daarvan in de geschiedenis van onze internationale positie ontbreekt.' ${ }^{1}$ Deze woorden van A. F. Manning uit 1987 hadden de redacteurs van Met man en macht ongewijzigd als verantwoording aan hun werk kunnen meegeven. Dit immers, zo stellen zij in hun woord vooraf, is de reden dat dit overzichtswerk is verschenen. De veertien (!) auteurs hadden als opdracht meegekregen de rol van een van de krijgsmachtdelen - landmacht of marine - in een bepaalde periode te beschrijven in het kader van de internationale positie waarin de Republiek/Nederland op dat moment verkeerde. Internationaal-politieke verhoudingen zijn het decor waarin het veiligheidsbeleid - in deze studie in nogal eng militaire zin gedefinieerd - wordt beschreven.

Het boek — de redacteuren wensten geen bundel opstellen — is een product van de in 1991 met private financiële middelen opgerichte stichting Schouwenburgfonds. Dit fonds stelt zich ten doel de beoefening van de militaire geschiedenis te bevorderen en heeft hiervoor onder meer een bijzondere leerstoel aan de Universiteit Leiden kunnen instellen. In 1995 kwam het bestuur met het plan een overzichtswerk van de Nederlandse militaire geschiedenis te laten maken. Het achtte de tijd hiervoor gekomen, nu de emancipatie van de militaire geschiedschrijving tot volwaardige academische discipline was bereikt. De oogst van bijna twee decennia modern militair historisch onderzoek zou aantonen dat Mannings constatering definitief tot het verleden behoorde.

Het woord vooraf gaat niet in op de voorgangers van dit overzichtswerk. Als negentiende- en vroeg twintigste-eeuwse oervaders van militaire overzichtswerken kan de volumineuze arbeid van J. Bosscha , J. C. de Jonge , F. de Bas , F. J. G. ten Raa en als samenvattend werk dat van I. L. Uijterschout gelden. ${ }^{2}$ In deze werken zien we de militaire geschiedenis nog in zijn oude, traditionele vorm van krijgsgeschiedenis. Het zijn studies naar veldslagen, naar de organisatie en de belangrijkste veldheren, waarin bij tijd en wijle luid op de nationalistische trom geslagen wordt. Wellicht met uitzondering van Wijns studie naar het leger van prins Maurits ${ }^{3}$ ontwikkelde de krijgsgeschiedenis zich geïsoleerd van de hoofdstroom van historisch onderzoek. Het was een terrein voor, veelal niet academisch geschoolde, specialisten. Bovendien kleefde aan het vak de pretentie dat er lessen voor contemporain militair optreden uit konden worden getrokken.

1 P. Luykx, N. Bootsma, ed., De laatste tijd. Geschiedschrijving over Nederland in de 20e eeuw (Utrecht, 1987) 278.

2 J. Bosscha, Neerlands heldendaden te land van de vroegste tijden af tot in onze dagen (Leeuwarden, 1834-1856); J. C. de Jonge, Geschiedenis van het Nederlandsche zeewezen (Haarlem, 1858-1862); F. de Bas, Prins Frederik der Nederlanden en zijn tijd (Schiedam, 1887-1904); F. J. G. ten Raa, Het Staatsche leger 1568-1795 (Breda-'s-Gravenhage, 1911-heden). I. L. Uijterschout, Beknopt overzicht van de belangrijkste gebeurtenissen uit de Nederlandse krijgsgeschiedenis van 1568 tot heden (Kampen, 1935). 3 J. W. Wijn, Het krijgswezen in den tijd van prins Maurits (Utrecht, 1934). 
Na de Tweede Wereldoorlog bleef deze situatie nog enkele decennia bestaan. Weliswaar verschenen zeer uitvoerige, en zeker ook kritische, publicaties over het optreden van het Nederlandse leger in de meidagen van 1940 en van het KNIL tijdens de Japanse aanval op Nederlands-Indië, het grote pubüek werd er niet mee bereikt. Ook werd het academisch debat er niet mee aangezwengeld. Pas in de jaren zeventig begon hier stap voor stap verandering in te komen. Het decennium opende met de publicatie van L. de Jongs deel over de meidagen van 1940 en J. A. A. van Doorns geruchtmakende studie over het Nederlandse optreden in Indonesie. ${ }^{4}$ Twee thema's die tot op de dag van vandaag hun actualiteit hebben behouden. In 1972 werd F. C. Spits de eerste academisch geschoolde historicus op de leerstoel militaire geschiedenis aan de universiteit van Utrecht. Twee jaar later promoveerde G. Teitler in Rotterdam op een sociologisch-militair-historische studie. ${ }^{5}$ De historische sectie van de Koninklijke Landmacht, opgericht in 1891, beleefde hetzelfde decennium zijn overgang naar een staf bestaande uit professionele historici. Het militair onderwijs volgde deze ontwikkeling.

De kleine groep militair historici in Nederland had veel achterstand in te halen. Het vak moest als specialisme erkenning zien te krijgen en zijn relevantie tonen door een bredere invulling van het onderzoeksterrein. De enge benaming krijgsgeschiedenis moest plaatsmaken voor militaire geschiedenis, waaronder ook sociale, economische en andere aspecten van het militaire bedrijf worden begrepen. De wisselwerking tussen krijgsmacht en samenleving in de breedste zin van het woord werd onderzoeksobject. Een voorbeeld hiervan is de reeks historische conferenties die de Stichting maatschappij en krijgsmacht vanaf 1984 tot 2003 organiseerde. De eerste handelde over de jaren dertig, de laatste sloot af met het einde van de Koude Oorlog.

Het vakgebied ging niet alleen de breedte, maar ook de diepte in. Een prachtig voorbeeld hiervan biedt de inleiding van John Keegan uit 1976 in zijn boek The face of battle. Keegan, zelf geen militair, toonde aan dat zelfs bij het traditionele onderwerp van de veldslag, nog vele aspecten onderbelicht waren. Hij introduceerde 'new military history', waarin het lot en de belevingswereld van de individuele soldaat centraal staan. Deze invalshoek is ook in de Nederlandse geschiedschrijving doorgedrongen.

Het vakgebied was in de jaren tachtig, toen Manning zijn woorden schreef, dus in beweging, in opmars. Op dat moment was het echter nog te vroeg te denken aan een overzichtswerk waarin militaire geschiedenis op een uitgebalanceerde wijze kon worden geïntegreerd in de 'mainstream'. De in de jaren 1977-1983 verschenen Algemene Geschiedenis der Nederlanden laat nog nauwelijks stappen op dit pad van integratie zien. Sindsdien is veel gebeurd, een blik in de bibliografie van Met man en macht toont al snel niet alleen het grote aantal, maar ook de diversiteit aan invalshoeken aan van publicaties sinds 1985.

Het specialisme van de militaire geschiedenis heeft zich heden ten dage definitief een plaats in de academische historische wereld veroverd. Met bijzonder hoogleraren aan de Universiteit van Amsterdam en de Universiteit Leiden en professionele onderzoeksinstellingen, verbonden aan de krijgsmachtdelen, is een hecht fundament gelegd en zijn veel nieuwe paden betreden. De keuze nu een overzichtswerk samen te stellen lijkt dan ook voor de hand liggend. Hiermee kan de stand van zaken op onderzoeksgebied aan een ruim publiek gepresenteerd worden. Toch wringt de schoen op een aantal punten als we deze maatstaf naast Met man en macht leggen. Twee zaken vragen een nadere beschouwing. Ten eerste de ondertitel, De militaire

4 J. A. A. van Doorn, W. J. Hendrix, Ontsporing van geweld. Over het Nederlands-Indisch-Indonesisch conflict (Rotterdam, 1970).

5 G. Teitler, De wording van het professionele officierskorps (Rotterdam, 1974). 
geschiedenis van Nederland 1550-2000, en ten tweede de samenhang tussen de opstellen. Hebben we hier te maken met een boek of een bundel opstellen?

Zoals reeds opgemerkt behandelt het werk de militaire aspecten van het veiligheidsbeleid van de Republiek en het koninkrijk, met uitstapjes naar de wereld van de militaire organisatie, het personeelsbeleid en de technologie. Het is hiermee meer de 'smalle' geschiedenis van het defensiebeleid dan 'brede' militaire geschiedenis geworden, zonder nadrukkelijk te definiëren wat onder defensiebeleid moet worden verstaan. De keuze van de periodisering onderstreept dit. Als cesuren gelden de vrede van Munster, het einde van de Zevenjarige Oorlog (1763), de definitieve val van Napoleon, het einde van het koloniale tijdperk, de oprichting van de NAVO en ten slotte het einde van de Koude Oorlog. Stuk voor stuk belangrijke momenten voor het Nederlandse defensiebeleid. Maar zijn het ook militair-historische cesuren? Oorlogvoering en politiek hangen vanzelfsprekend nauw samen, maar ontwikkelingen op krijgskundig gebied zijn niet per definitie logische aanhangsels van politieke beslissingen. Een werk dat zich de militaire geschiedenis van Nederland noemt, moet toch duidelijk maken wat militaire geschiedenis eigenlijk is. Wat in de kern de ontwikkelingen zijn van een opstandige guerrilla te land en ter zee in de zestiende eeuw, die het opnam, via een Staats leger en vloot, tegen een wereldrijk, tot een dienstplichtkrijgsmacht van een kleine mogendheid en ten slotte een beroepskrijgsmacht voor internationale vredeshandhaving. Aan deze ontwikkelingen kleven sociale, wapentechnische, financiële, en militair-operationele aspecten. De rol van de militaire organisatie in de Nederlandse geschiedenis zou toch zeker deze aspecten moeten omvatten, alle ingekaderd in de grotere politieke en sociaal-economische ontwikkelingen. We onderkennen internationaal een 'military revolution' ${ }^{6}$ in de zestiende en zeventiende eeuw, we kennen het begrip totale oorlog als karakteristiek voor de twintigste eeuw, maar hoe moeten we de Nederlandse praktijk en opvattingen hierin plaatsen?

Dit te analyseren is wellicht een ideaal voor de toekomst, op basis van de huidige stand van onderzoek kan er wel iets over worden gezegd, al is er nog geen compleet beeld. Er zijn zelfs duidelijke blinde vlekken. Zo ontbreken moderne militair-historische analyses van de strijd met België (1830-1839) en van de Nederlandse krijgsmacht in de Eerste Wereldoorlog en het interbellum. Juist de interbellumjaren stonden bol van de discussies over wat de technische en operationele lessen van de Eerste Wereldoorlog nu waren en hoe dus de defensie vorm gegeven moest worden. Internationaal zijn er voorbeelden te vinden van militair-historische overzichtswerken, die wellicht inspirerend kunnen werken. Te denken valt aan Grundzüge der deutschen Militärgeschichte en het Handbuch zur deutschen Militärgeschichte, 1648-1939.",

Discussies zijn opmerkelijk afwezig in Met man en macht. Historiografische controverses of verschillen van inzicht over bijvoorbeeld de achtergronden van de nederlaag in de meidagen van 1940, over de strijd in de Indische archipel, over hoe de invulling van de neutraliteit in politieke en militaire zin beoordeeld moet worden, of over de Nederlandse rol in de NAVO komen niet aan de orde. Ook in een verder verleden liggen kwesties van belang zoals de beoordeling van de Nederlandse vestingbouw of van wapenproductie in de late zestiende tot de achttiende eeuw in Europees perspectief, of de rol van de logistiek (bevoorrading), maar die

6 Zie G. Parker, The military revolution. Military innovation and the rise of the west (Cambridge, 1996).

7 Opmerkelijk is het ontbreken van een hoofdstuk over Nederland in de bundel van S. Förster, An der Schwelle zum Totalen Krieg (Paderborn, 2002). Zwitserland en België zijn hierin wel vertegenwoordigd.

8 K. V. Neugebauer, Grundzüge der deutschen Militärgeschichte (Freiburg, 1993). H. Meier Welcker, Handbuch zur deutschen Militärgeschichte, 1648-1939 (München, 1979-1981). 
komen niet of nauwelijks aan bod. ${ }^{9}$ De Nederlandse militaire geschiedenis is veel spannender en dynamischer dan dit boek doet vermoeden. Een beredeneerde bibliografie had dit kunnen ondervangen. Ook het inleidende karakter van het werk zou een dergelijke bibliografie rechtvaardigen. Jammer is dat nu is volstaan met opsommingen van gebruikte literatuur per hoofdstuk, waarin nogal wat redundantie zit. ${ }^{10}$

Ten tweede dringt de vraag naar de samenhang tussen de opstellen zich op. In het woord vooraf stellen de redacteuren nadrukkelijk dat het niet de bedoeling was een bundel samen te stellen. Toch heeft het werk kenmerken van een bundel behouden. Door de keuze iedere periode zowel vanuit het perspectief van de strijd te land als vanuit dat van de strijd ter zee te behandelen, waren overlappingen onvermijdelijk. We zien elk belangrijk conflict tweemaal langskomen, in een enkel geval driemaal als het ook de koloniale oorlogen betreft. Deze keuze weerspiegelt de institutionele inkadering van de militaire geschiedschrijving in Nederland. Landmacht en marine leven nog nadrukkelijk in hun eigen historische wereld. Joint optreden, zoals de fraaie militaire term luidt, gebeurt dan wel meer en meer in de dagelijkse praktijk van de krijgsmacht, in de geschiedschrijving is het nog een zeldzame exercitie. Juist in een werk dat veiligheidsbeleid als focus kiest, hadden de redacteuren de uitdaging moeten oppakken van de krijgsmachtdeelgerichte benadering af te stappen. Toegegeven, dat is gemakkelijker gezegd dan gedaan. Studies waarin maritieme en landmachtgerichte elementen daadwerkelijk geïntegreerd worden behandeld zijn uitermate schaars, maar zolang dat niet gebeurt lijkt het alsof de Republiek/Nederland er twee gescheiden 'defensiebeleiden' op na hield, en dat nog eens verdubbeld in de koloniën.11

De in de inleiding beloofde analyse van het (mijn curs.) defensiebeleid komt zo nog onvoldoende uit de verf. Dat de krijgsmachtdelen leger en marine evenwichtig in een boek behandeld worden, is daarentegen wel een belangrijke eerste stap, maar het smaakt toch nadrukkelijk naar meer omdat de scheiding per krijgsmachtdeel de interne samenhang juist afbreuk doet. In dit verband is de (bijna) afwezigheid van de andere krijgsmachtdelen opmerkelijk. Op de cover staan weliswaar de vier emblemen van de Nederlandse krijgsmachtdelen afgebeeld, de luchtmacht en de marechaussee komen toch nauwelijks aan bod. Juist de luchtmacht biedt een aardige kapstok iets te zeggen over technologisering, over de relatie tussen krijgsmacht en industrie, over schaalvergroting van de oorlogvoering enzovoort. Dat de Koninklijke Marechaussee er bekaaid afkomt is niet zo vreemd. Deze organisatie is nog maar enkele jaren een krijgsmachtdeel en het professioneel historisch onderzoek ernaar staat nog in de kinderschoenen. Toch lagen ook hier kansen. Recent publiceerde R. van der Wal zijn studie over militaire bijstand $^{12}$ en de huidige werkzaamheden van de marechaussee in het kader van het vreemdelingen- en anti-terreurbeleid illustreren een nieuwe rol van de krijgsmacht.

Het zou in dit verband te ver voeren alle veertien bijdragen te behandelen. Enkele wil ik noemen. Olaf van Nimwegen heeft een heldere bijdrage geschreven over de periode 1650-

9 Een recent overzichtswerk op dit gebied hebben de auteurs niet meer kunnen meenemen: H. Roos, ed., Van marketentster tot logistiek netwerk. De militaire logistiek door de eeuwen heen (Amsterdam, 2003).

10 Zie voor een overzicht van de Nederlandse militaire geschiedschrijving B. Schoenmaker, 'Clio at arms: military history in the Netherlands', Mededelingen van de sectie militaire geschiedenis, XIV (1991) 82-104 en Revue internationale d'histoire militaire (Den Haag, 1984).

11 J. A. M. M. Janssen, 'Driestromenland in optima forma' in: B. Schoenmaker, J. A. M. M. Janssen, ed., In de schaduw van de muur. Maatschappij en krijgsmacht rond 1960 (Den Haag, 1997).

$12 \mathrm{R}$. van der Wal, Militaire bijstand hij de handhaving en het herstel van de openbare orde (Utrecht, 2002). 
1750. Het is een uitgebalanceerd hoofdstuk over de rol van de Republiek in de gecompliceerde internationale verhoudingen van die honderd jaar in combinatie met een analyse van de samenstelling, organisatie en bewapening van het Staatse leger. Van Nimwegen weet een fraaie balans te vinden tussen het grote kader en het illustratieve, militair-historische detail. Enkele illustraties van wapens en tactieken waren hier wel op hun plaats geweest, deze hadden, samen met een geïllustreerde uitleg over hoe nu een veldslag verloopt, de bijdrage voor niet-specialisten nog verhelderd. Ook de bijdrage van Jaap de Moor verdient lof. In iets meer dan veertig pagina's schetst De Moor de Indische militaire geschiedenis in hoofdlijnen. Het is, net als de bijdrage van Van Nimwegen, een uitstekende samenvatting gebaseerd op een goede kennis van de nieuwste historische inzichten. Idealiter had De Moors bijdrage met die van Anita van Dissel over de maritieme aspecten van de Nederlandse aanwezigheid in de archipel tot een hoofdstuk samengevoegd moeten worden. Overlap tussen deze hoofdstukken is nu soms storend.

Willem Bevaart ten slotte legt in zijn bijdrage duidelijk uit welke rol het leger speelde in de politieke ambities van de koningen Willem I en II en hoe Nederland de overgang maakte van een ambitieuze middelgrote mogendheid tot een kleine neutrale staat waarin het koninklijke gezag was teruggedrongen. Bevaart is er goed in geslaagd aan te tonen hoe het militaire element een belangrijke factor in deze ingrijpende transitie was.

Met man en macht vult een lacune in de Nederlandse historiografie. Het Schouwenburgfonds verdient zeker complimenten dat het het aandurfde het eerste overzicht van de Nederlandse militaire geschiedenis sinds Uijterschout uit te geven. Vooral voor de wereld buiten de vakspecialisten is nu een gemakkelijk toegankelijke ingang beschikbaar. Om in militaire termen te spreken, een tussengelegen aanvalsdoel is genomen, in de verte doemt het volgende doel al op: een handboek waarin militaire geschiedenis in haar breedte en maatschappelijke inkadering wordt behandeld. 


\section{Recensies}

\section{ALGEMEEN}

C. A. Tamse, Het Huis van Oranje en andere politieke mythen (Amsterdam: Bert Bakker, 2002, 491 blz., € 27,95, ISBN 903512401 4).

Een jaar na zijn afscheid als hoogleraar in de geschiedenis van de politieke cultuur aan de Rijksuniversiteit in Groningen verscheen deze bundel verspreide geschriften van Coen Tamse, samengesteld door Remieg Aerts, Klaas van Berkel, Janny de Jong en Henk te Velde. De laatste schreef een inleiding over persoon en werk van de schrijver en de 17 artikelen worden gevolgd door een overzicht van de publicaties van Tamse.

In de gekozen artikelen zijn de belangrijkste thema's van het werk van Tamse vertegenwoordigd: geschiedenis van de internationale betrekkingen met de nadruk op de relaties tussen Nederland en België in de negentiende eeuw en verder natuurlijk de geschiedenis van de $\mathrm{Ne}$ derlandse monarchie. Bij het laatste onderwerp krijgt koningin Sophie, met wie Tamse zich intensief heeft beziggehouden, terecht veel aandacht. In één bijdrage van recente datum geeft hij een boeiend verslag van zijn 'werk in uitvoering' voor een biografie van deze bijzondere vorstin. De lezer kan alleen maar hopen dat de werkzaamheden nog voortgezet worden. In diverse bijdragen blijkt tegelijkertijd de belangstelling van Tamse voor onderwerpen als Engeland en de geschiedenis van de Engelse monarchie, beeldvorming in internationale relaties evenals voor het gebruik van autobiografisch materiaal.

Uit de herkomst van de artikelen blijkt de diversiteit van zijn publicaties. Behalve bijdragen aan tijdschriften en bundels in binnen- en buitenland zijn ook twee stukken uit NRC Handelsblad opgenomen, over de rechten van de mens en over Lodewijk XVIII. Over het geheel genomen dus lof voor de samenstellers, maar in sommige gevallen hebben ze in hun selectie misschien wat veel overlappingen en doublures voor lief genomen. Dat geldt met name voor de overzichten van de geschiedenis van de Nederlandse monarchie en voor de behandeling van koningin Wilhelmina.

Over de artikelen zelf, alle al eerder gepubliceerd, slechts een enkele opmerking - immers goede wijn behoeft geen krans. Aangevuld door de waardevolle inleiding van Te Velde laten ze belangrijke aspecten van het werk van Tamse zien zoals vakgenoten het de afgelopen decenniën hebben leren kennen, erudiet en gedegen, verzorgd en helder geschreven. Opnieuw valt de brede opzet en aandacht voor achtergrond en context op, of het nu gaat over de geschiedenis van de Nederlandse monarchie in de negentiende eeuw of de collecties van het Huis van Oranje. Scherpzinnige analyses geven ook in overzichten van bekend terrein telkens weer nieuwe perspectieven. De veranderingen in de functie van de Nederlandse monarchie en met name haar nieuwe sociaal integratieve functie worden in een Europese context geplaatst, waarbij België en Engeland vanzelfsprekend de meeste aandacht krijgen. Voor Tamse kan de monarchie, en zeker die onder het Huis van Oranje, ook in de moderne tijd nog een belangrijke functie hebben, mits ze 'vaste geloofswaarden en zekerheden' (241) niet verloochent. Terecht geven de samenstellers in hun 'Woord vooraf' aan dat de keuze van de titel enigszins uitdagend is. Weliswaar behelst het eerste artikel een historische analyse van het begrip 'politieke mythe' en spreekt de auteur hier en in andere bijdragen van 'de Oranjemythe', maar het vor- 